\title{
Major Advances Associated with Environmental Effects on Dairy Cattle
}

\author{
R. J. Collier, ${ }^{\star 1}$ G. E. Dahl, $†$ and M. J. VanBaale* \\ *Department of Animal Sciences, University of Arizona, Tucson 85721 \\ †Department of Animal Sciences, University of Illinois, Urbana 61801
}

\section{Abstract}

It has long been known that season of the year has major impacts on dairy animal performance measures including growth, reproduction, and lactation. Additionally, as average production per cow has doubled, the metabolic heat output per animal has increased substantially rendering animals more susceptible to heat stress. This, in turn, has altered cooling and housing requirements for cattle. Substantial progress has been made in the last quarter-century in delineating the mechanisms by which thermal stress and photoperiod influence performance of dairy animals. Acclimation to thermal stress is now identified as a homeorhetic process under endocrine control. The process of acclimation occurs in 2 phases (acute and chronic) and involves changes in secretion rate of hormones as well as receptor populations in target tissues. The time required to complete both phases is weeks rather than days. The opportunity may exist to modify endocrine status of animals and improve their resistance to heat and cold stress. New estimates of genotype $\times$ environment interactions support use of recently available molecular and genomics tools to identify the genetic basis of heatstress sensitivity and tolerance. Improved understanding of environmental effects on nutrient requirements has resulted in diets for dairy animals during different weather conditions. Demonstration that estrus behavior is adversely affected by heat stress has led to increased use of timed insemination schemes during the warm summer months to improve conception rates by discarding the need to detect estrus. Studies evaluating the effects of heat stress on embryonic survival support use of cooling during the immediate postbreeding period and use of embryo transfer to improve pregnancy rates. Successful cooling strategies for lactating dairy cows are based on maximizing available routes of heat exchange, convection, conduction, radiation, and evaporation. Areas in dairy operations in which cooling systems have been used to enhance cow comfort, improve milk production, reproductive efficiency, and profit in-

Received August 31, 2004

Accepted May 23, 2005.

${ }^{1}$ Corresponding author: rcollier@ag.arizona.edu clude both housing and milking facilities. Currently, air movement (fans), wetting (soaking) the cow's body surface, high pressure mist (evaporation) to cool the air in the cows' environment, and facilities designed to minimize the transfer of solar radiation are used for heat abatement. Finally, improved understanding of photoperiod effects on cattle has allowed producers to maximize beneficial effects of photoperiod length while minimizing negative effects.

Key words: environment, heat stress, photoperiod, adaptation

\section{INTRODUCTION}

A majority of the world's human and domestic animal populations lies in regions where seasonal stressors adversely influence productivity. Annual economic losses due to heat stress alone for the US dairy industry have been estimated at $\$ 900$ million. Our understanding of the mechanisms by which environmental stress reduces productivity of domestic animals has greatly improved over the last quarter-century. Likewise, decades of research using genetically defined populations demonstrated that use of conventional crossbreeding approaches to improve resistance to thermal stress always lowers milk yields in the $\mathrm{F}_{1}$ generation. Therefore, improving productivity in dairy animals exposed to adverse environmental conditions during the last quartercentury has focused on improving the environment around the animals and improving their nutritional management while applying selection pressure on improving yields rather than improving resistance to stressors. This approach has dramatically increased productivity of dairy animals. However, as energy costs have increased, the return on investment for modifying environments around animals has declined. Therefore, there is renewed interest in lowering energy costs of cooling as well as an interest in identifying specific genes, which could improve resistance to stressors without adversely affecting productivity.

\section{PHYSIOLOGICAL RESPONSES TO ENVIRONMENT}

The basic thermoregulatory strategy of a mammal is to maintain a body core temperature higher than 
ambient temperature to allow heat to flow out from the core via 4 basic routes of heat exchange (conduction, convection, radiation, and evaporation). Three of these routes (conduction, convection, and radiation) are referred to as sensible routes of heat loss and require a thermal gradient to operate. The fourth (evaporation) works on a vapor/pressure gradient and is defined as insensible heat loss. When ambient temperature conditions approach body temperature, the only viable route of heat loss is evaporation; if ambient conditions exceed body temperature, heat flow will reverse and the animal becomes a heat sink. Therefore, estimating the thermal environment around animals is key to understanding their cooling needs. Estimating impact of ambient conditions around animals on their performance has been done using the temperature-humidity index (THI) that takes into account ambient air temperature and humidity. This can be improved using a black globe humidity index, which adds the impact of solar radiation on ambient conditions around animals. However, these indices are most accurate for estimating the conditions outside a housing structure. Due to location of cooling equipment relative to animals and the positions of the animals themselves in the structure, there is a wide variety of microenvironments present in the structure to which animals are exposed. Therefore, it has been difficult to judge whether animals in housing systems are being adequately cooled. Recently, use of infrared thermography guns has been shown to be a low-cost approach to estimate actual skin surface temperature of animals. If the skin surface temperature is below $35^{\circ} \mathrm{C}$, the temperature gradient between the core and skin is large enough for the animals to effectively use all 4 routes of heat exchange.

As shown in Figure 1, infrared skin temperature is highly correlated with respiration rates and is a good measure of the microenvironment around the animal. Furthermore, the measurement can be taken from a distance, which does not require restricting movement of the animals. Recently, researchers have tracked core body temperature using new intravaginal probes attached to continuous intravaginal drug release (CIDR) devices for practical on-farm use (Figure 2). These devices remain inside the cow's vagina measuring core body temperature (CBT) every $60 \mathrm{~s}$ for up to $6 \mathrm{~d}$. This technology allows cows' CBT to be monitored and recorded $24 \mathrm{~h} / \mathrm{d}$ as they move throughout all areas of a dairy facility.

The nutrient needs of the cow are altered by thermal stress requiring changes in ration reformulation. Changes include decreased DMI requiring increased nutrient density, altered mineral and water requirements, and altered digestive tract function. Heat stressinduced negative energy balance reduces milk yield and reproductive performance and efficiency and is costly to the dairy industry. Management procedures typically used to avoid negative effects in performance are to increase dietary energy density (via increased grain and or increased fat). Increased sweating rate in heatstressed cows increases potassium requirements by as much as $12 \%$ because sweat in cattle is high in potassium and low in sodium. This is less of an issue when forages are used in the diet but can be limiting to production in diets based on by-product feed sources. Supplemental rumen-active fat has advantages over starch-based concentrate to increase energy density of diets for lactating cows during the warm summer months. Addition of fungal cultures to dairy diets has been shown to reduce respiration rate and body temperature during thermal stress in several studies. Rumen acidosis is often increased under heat-stress conditions associated with reduced forage intake and increased high energy feed intake. A number of studies have shown that increased buffering of the rumen during thermal stress is warranted. Much remains to be learned about maximizing nutrient intake and use in lactating dairy cows subjected to thermal stress.

Reproductive performance of lactating cows is greatly reduced during thermal stress but nonlactating heifers generally show no seasonal trend in reproductive performance even in the humid Southeastern United States. Both expression of estrus and fertility are reduced in heat stressed lactating cows. Tools and methods for timed inseminations have been developed that reduce the need for detection of estrus. When timed AI programs were used, pregnancy rates were improved under thermal stress conditions compared with AI without timing. Recent reports indicate that calving in the summer months might reduce the success of a timed first insemination between 60 and $66 \mathrm{~d}$ postpartum, although other researchers have reported increased conception rates under similar conditions. Follicular dynamics are altered by thermal stress, and oocyte quality is reduced for an extended interval after thermal stress is removed. This is believed to be the reason for decreased fertility of dairy cows during cooler autumn months. Enhanced removal of the impaired cohort of follicles led to earlier emergence of healthy follicles and higher quality oocytes. Embryo transfer has also been reported to improve pregnancy rates during warm summer months by removing the need to detect estrus. Use of AI during summer avoids the negative effects of heat stress on bull performance on dairies. Dry pregnant cows are often given little protection from thermal stress because they are not lactating. However, several studies have demonstrated that heat stress of dry pregnant cows lowered birth weight of calves and reduced milk yields in the next lactation. Additional work is 


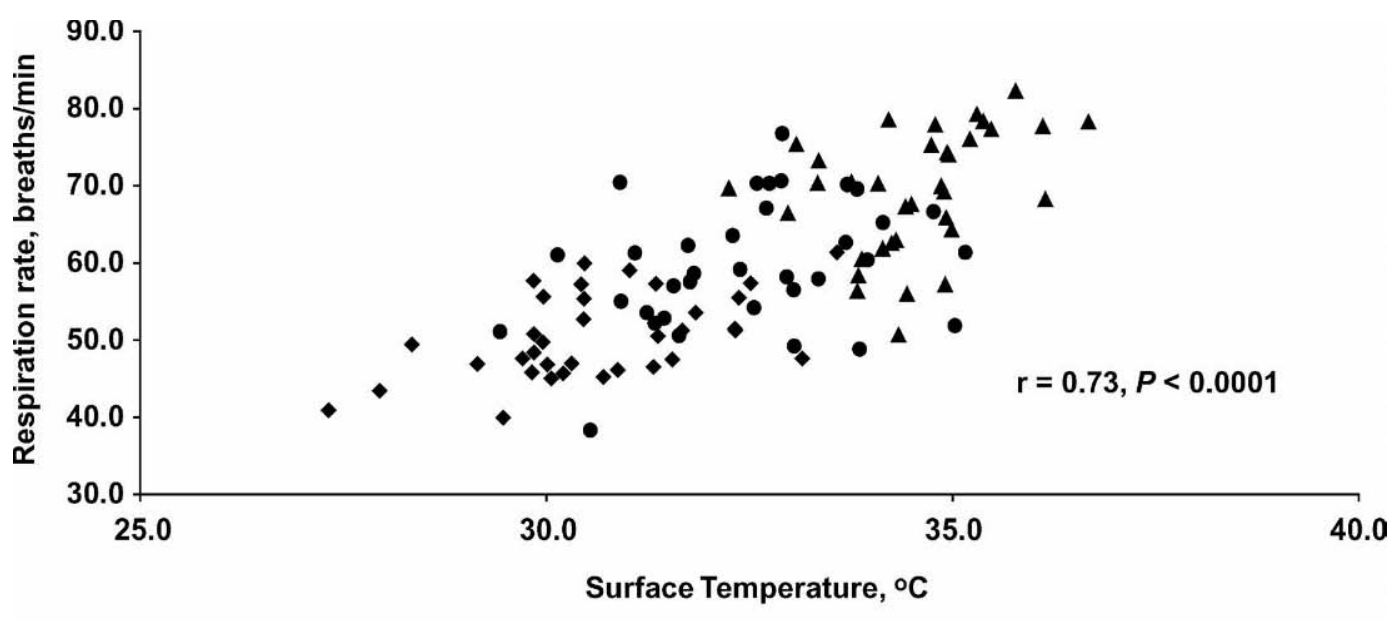

- Pen 1 - Pen 3 A Pen 6

Figure 1. Correlation between surface temperature and respiration rate in Holstein cows. Data points represent individual left-side infrared surface temperature and respiration rate per minute of Holstein cows under 3 different shade management systems (in pens 1,3 , and 6) that included oscillating fans with misters, Shade Tracker (pen 1, (); reverse chimney fans with misters, Korral Kool (pen 3, ); or fans alone (pen 6, $\mathbf{\Delta}$ ). All temperature readings were taken between 1300 and $1500 \mathrm{~h}$ between June and September 2001 in Tucson, AZ.

warranted to improve reproductive performance of cattle in hot environments as well as effects of heat stress during the transition period on subsequent lactation.

Acclimation to changes in thermal environment and photoperiod are homeorhetic processes that are commonly referred to as seasonal changes in domestic animal biology. Acclimation involves changes in hormonal signals as well as alteration in target tissue responsiveness to hormonal stimuli. Improving our understanding of this process will lead to improved genetic

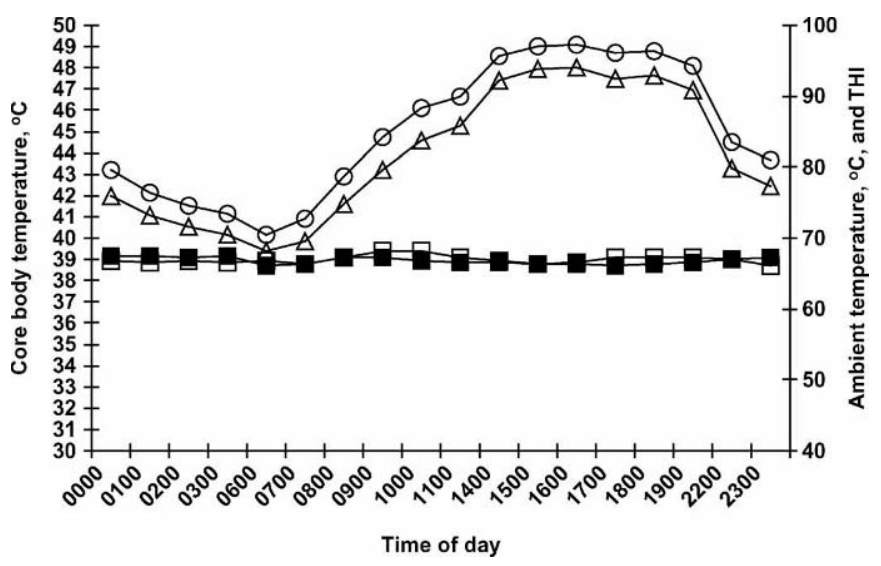

Figure 2. Vaginal body temperature of cows cooled with Advanced Dairy System-Shade Tracker (ADS-ST; $\square$ ) or Korral Kool (KK; $\mathbf{0}$ ), outside ambient temperature $(\triangle)$, and temperature-humidity index (THI; O) (minus milking times) from August 25 to August 28, 2004. Temperature data were obtained from the Arizona Meteorological Network weather station approximately 1 mile from the experimental site. selection of heat stress-resistant genotypes. Hormones known to be homeorhetic regulators are also implicated in acclimatory responses to thermal stress and altered photoperiod. These include thyroid hormones, prolactin (PRL), somatotropin (ST), glucocorticoids, and mineralocorticoids. One example of acclimatory change in an endocrine regulator is the seasonal rhythm in PRL concentration when animals acclimate to seasonal changes in temperature and day length. The hypothalamic-pituitary-adrenal axis including corticotropin-releasing hormone, adrenocorticotropic hormone (corticotrophin), cortisol, and aldosterone are also altered by thermal stress and are involved in acclimatory responses to thermal stress. Corticotropin-releasing hormone stimulates somatostatin release from the hypothalamus, which can inhibit secretion of ST and thyroid stimulating hormone from the pituitary and down-regulate the thermogenic effects of both ST and thyroid hormones. In dairy cattle, the glucocorticoids decrease during acclimation at $35^{\circ} \mathrm{C}$ and are lower in thermally acclimated animals compared with controls. There is evidence for a biphasic pattern of heat acclimation divided into periods based on time. Short-term heat acclimation (STHA) is the phase where changes begin to take place within cellular signaling pathways. These changes create disturbances in cellular homeostasis and begin to reprogram cells to combat the deleterious effects of heat stress. When all of the changes occurring during STHA are complete and the heat-acclimated phenotype is expressed, longterm heat acclimation (LTHA) has occurred. Development of genomics tools has permitted a much better 
evaluation of the genotype $\times$ environment interactions (GXE). Recent estimation of GXE effects in dairy cattle have indicated these effects are larger than originally thought. Furthermore, genetic differences in heat tolerance between animals appear to be exacerbated under high temperature conditions. For example, preimplantation embryos from Bos indicus cattle are better able to withstand thermal stress than are embryos from Bos taurus cattle. Thus, identifying genetic causes of differences between animals in their response to the environment has potential for improving productivity of animals in adverse environments. The ability to use powerful new tools in genomics, proteomics, and metabolomics to evaluate genetic differences between animals in their response to thermal stress will yield important new information in the next quarter-century and will permit the selection of cattle for resistance to thermal stress.

\section{IMPACT OF COOLING SYSTEMS AND FACILITIES ON HEAT STRESS IN DAIRY COWS}

\section{Shades}

Shade for dairy cows (protection from solar radiation) is considered essential to minimize loss in milk production and reproductive efficiency. It was estimated that total heat load could be reduced from 30 to $50 \%$ with a well-designed shade. Cows in a shade vs. no shade environment had lower rectal temperatures (38.9 and $39.4^{\circ} \mathrm{C}$ ), reduced respiratory rate $(54$ and 82 breaths/ min), and yielded $10 \%$ more milk. Similarly, Florida workers observed that cattle with no shade had reduced ruminal contractions, higher rectal temperature, and reduced milk yield compared with shaded cows. Researchers at the University of Arizona reviewed shade and cooling for cows and discussed the benefits and deficiencies of various types of shade. Armstrong suggested that the location and size of the shade is important, and differing shade orientations are necessary depending on whether the application is in a dry or wet climate. Regardless of climate, a mature dairy cow requires 3.5 to $4.5 \mathrm{~m}^{2}$ of space beneath the shade, and a north-south orientation to allow for penetration of sunlight beneath the shade for drying the ground. Inadequate space for shading may result in udder injury as cows crowd together, and excessive shade space has no benefits, as cows tend to group together. Shades should be at least $4.3 \mathrm{~m}$ high to decrease the amount of reflected solar radiation from the shade roof to the cow. Using a more porous material such as shade cloth or snow fence is not as effective as solid shade.

Although temperature was reduced by $10^{\circ} \mathrm{C}$ when insulated vs. noninsulated shade roofing was compared, the cost and practicality of insulated roofing has de- terred extensive use. Although reflective coatings can reduce the temperature of galvanized roofing, the coatings add expense and effectiveness drops rapidly with time due to reduced reflectivity. In addition, the reflective coatings added little benefit to well-ventilated facilities. Although shade reduces heat accumulation from solar radiation, there is no effect on air temperature or relative humidity; thus, additional cooling is required for lactating cows in a hot, humid climate. In the past 25 yr, foggers (vapor condensed to fine particles of water), misters (a fine spray of particles of water), and sprinklers (a scatter of liquid in fine drops of water) have been used to modify water particle size in an effort to effectively cool cows.

\section{Holding-Pen Cooling}

The holding pen is where dairy cows experience the most heat stress. A lactating cow will spend 15 to 75 min before milking in the holding pen adjacent to the milking parlor. Increased milk production $(0.8 \mathrm{~kg} / \mathrm{head}$ per $\mathrm{d})$ and a reduced body temperature $\left(1.95^{\circ} \mathrm{C}\right)$ occur when sprinklers (not foggers) and fans were installed in the holding pen area. Sprinklers should run in cycles based on temperature and humidity and fans should be mounted overhead and blow downward at a $30^{\circ}$ angle. Fans are typically placed side-by-side and 1.8 to $2.4 \mathrm{~m}$ apart, and the distance between rows of fans is $6.1 \mathrm{~m}$ for 76.2 - and 91.4-cm fans and $12.2 \mathrm{~m}$ for 121.9$\mathrm{cm}$ fans. Water should be sprayed (1 min out of every 6) onto the cows using a polyvinyl chloride grid of 360 nozzles. The majority of dairy operations in the western US should consider holding-pen cooling.

\section{Exit-Lane Cooling}

To increase cooling beyond the milking period, parlor exit sprinklers should be installed in exit lanes in climates such as that in Arizona. When a cow enters a corral with a wet body surface, the moisture will evaporate and cool the cow for an additional 15 to $25 \mathrm{~min}$ depending on weather conditions. Typical exit-lane sprinklers include nozzles ( $\sim 3$ to 4 nozzles) with a delivery of $30 \mathrm{~L}$ of water/min at 35 to $40 \mathrm{psi}$. It is recommended that nozzles be located $0.3 \mathrm{~m}$ behind the control switch to begin water application as the head passes through while assuring that water is not sprayed into the ear cavity. If properly installed, sprinklers should wet the top and sides of the cow, the udder will remain dry, and the water will not interfere with postdip.

\section{Free-Stall Cooling}

Much of the emphasis on environmental modifications in the US dairy industry has focused on the use 
of free-stall and loose housing barns with high, steeply pitched (4/12 pitch) roofs, often with open or capped ridge vents. Data collected from 41 free-stall barns containing 30 different cooling systems, several roof designs, and from 14 barns with no cooling systems indicated that the most effective cooling system was a spray and fan system, followed by the orchard fan system, and the feed-line spray only. The high-pressure fogger system showed the poorest results for cow comfort. The range within each system (except for the high pressure fogger system) demonstrated that each system was capable of effective cooling, depending on installation. Specifically, Armstrong et al. (1999) reported that cows housed under feed-line spray and fan systems had a lower percentage increase in respiration rate for feedline spray systems closest to the cow. In addition to cooling systems, they reported that free stalls should be constructed to provide good natural ventilation. Sidewalls should be $4.3 \mathrm{~m}$ high to increase the volume of air in the housing area, and sidewalls should open 75 to $100 \%$. Roofs with slopes steeper than 6/12 pitch prevent incoming air from dropping into the area occupied by the cows, and roofs with slopes less than 4/12 may cause condensation and higher internal temperatures in the summer. The ridge opening should be $5 \mathrm{~cm}$ for each $3 \mathrm{~m}$ of free-stall building width. Most free-stall cooling trials have been more successful at cooling the cows in the feed-line area using spraying fans and misters (see below) than cooling the cow in the bedded stall.

\section{SPRINKLER AND FAN COOLING SYSTEMS UNDER SHADED HOUSING}

Early work from Louisiana showed cooling benefits from air movement and wetting the cow's body surface. They reported that sprinkling cows before entering a shade reduced respiration rate by 65 to $81 \%$ and body temperatures by 46 to $50 \%$ over shade alone. They concluded that using sprinklers in combination with supplemental airflow was superior to a fan alone or sprinkling. Similarly, Florida researchers reported an $11.6 \%$ improvement in milk yield when cows were sprayed for $1.5 \mathrm{~min}$ of every $15 \mathrm{~min}$. Cooled cows had sharply reduced respiratory rate (57 vs. 95 breaths/min), and efficiency of production ( $\mathrm{kg}$ of milk per $\mathrm{kg}$ of DMI) was improved for cooled cows. Sprinkler and fan cooling systems generate a large volume of water that must be processed. The cooling system used by Florida researchers used $454 \mathrm{~L} /$ cow per d, which totaled 54,504 L/cow for a 120-d cooling season. However, when differing rates of water application for cooling were compared, a system using $313 \mathrm{~L} / \mathrm{h}(216 \mathrm{~L} /$ cow per $\mathrm{d}$,) cooled cows as effectively as a system delivering $704 \mathrm{~L} / \mathrm{h}$. Large droplets from a low-pressure sprinkler system that com- pletely wets the cow by soaking through the hair coat to the skin is more effective than a misting system. A combination of fans and misters was as effective as fans and sprinklers at maintaining intake and milk yield. However, the fan/sprinkler system used about 10-fold more water than did the fan/mist system. Thus, attention to water delivery rate through nozzle size or the use of fans and misters has proven effective in cooling cows, and used substantially less water than systems evaluated in earlier research. Studies from Missouri and Israeli showed milk yield increases of $0.7 \mathrm{~kg} / \mathrm{d}$ in moderate temperatures and $2.6 \mathrm{~kg} / \mathrm{d}$ in warm, humid conditions.

Most recently, Kansas State researchers evaluated several different treatments using sprinklers and airflow. Body and surface temperature of the rear udder and thurl were monitored every 5 min during the study. Body temperature (Figure 3) dropped most rapidly when soaking the cow every 5 min in addition to providing supplemental airflow. Fans alone did not significantly reduce body temperature. Increased sprinkling frequency reduced body temperature when used in conjunction with supplemental airflow. The surface temperatures of the rear udder and thurl showed a similar pattern as body temperature.

\section{EVAPORATIVE COOLING SYSTEMS}

Evaporative cooling systems have improved the environment for lactating dairy cows in arid climates. These systems use high pressure, fine mist, and large volumes of air to evaporate moisture and cool the air surrounding the cow. There are questions regarding the effectiveness of evaporative systems in climates with high relative humidity because when relative humidity increases above $70 \%$, the potential reduction in THI is less than $10 \%$. Florida researchers used evaporative cooling pads to effectively reduce air temperature of the barn, rectal temperature, and respiratory rate. Similarly, cows in Mississippi that were cooled using evaporative pads had reduced respiratory rate and body temperature and slight increases in DMI with little or no effect on milk yield. High-pressure mist injected into the fan stream, with fans directed downward to blow cooled air on the cow cooled cows equally as well as a low-pressure sprinkler and fan system. However, positioning of fans and misters was important and much more effective when mounted low near the cow and much less effective when mounted higher in the barn.

An evaluation of evaporative cooling approaches under semiarid conditions was carried out utilizing 80 cows balanced for parity, stage of lactation, and milk yield randomly assigned to Korral Kool (KK) or Advanced Dairy System Fan (ADS) cooling systems. Each 


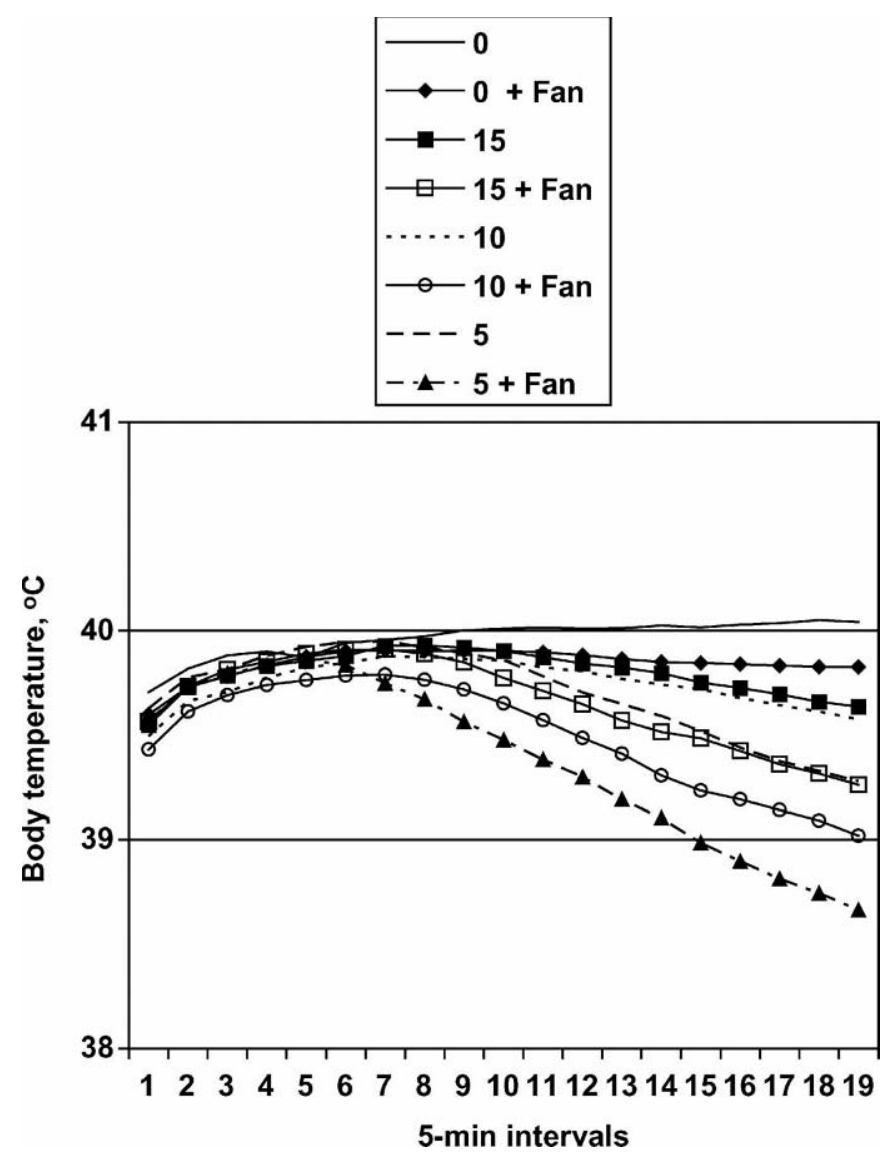

Figure 3. Effect of cooling systems (water with and without airflow) upon body temperature over 95 min of cooling. The solid line represents no fan and no water applied; the solid line with closed diamonds represents fan only; the other curves represent water applied for 1 min out of 15-, 10-, and 5-min periods, respectively, with and without fans. Fan speed was $213.4 \mathrm{~m}^{3} / \mathrm{min}$ and water was applied at $1.54 \mathrm{~L} /$ headlock per min; several 5 -min periods are represented on the x-axis for the total 95-min cooling period. All temperature readings were taken in the tie-stall barn at the Kansas State University Dairy Teaching and Research Unit, Manhattan, KS.

pen included a shade structure oriented north-south. The KK pen had 3 overhead coolers, with computerdriven, variable-speed fans and variable-pressure water injection into the air stream. The ADS pen had 3 computer-driven fans with a variable-speed water injection into the air stream placed below the western edge of the roof. The arc of the ADS fans was $270^{\circ}$. The KK system varied fan speed and water injection according to THI, whereas the ADS varied water injection according to THI. Water and electrical use was metered on each system. Water use was higher for ADS compared with KK. However, electrical use was lower for ADS compared with KK. Temperature and humidity recorders established THI outside and under each shade. Mean THI outside the shades was 80. Mean THI was higher under ADS compared with KK (78 vs. 77,
$P<0.001)$. Thermal status of cows was established via infrared gun and visual observation of respiration rate (RR). Average cow surface temperature was higher for ADS compared with $\mathrm{KK}$ (34.3 vs. $\left.26.6^{\circ} \mathrm{C}\right)$. Likewise, respiration rate was higher in $\mathrm{ADS}$ cows compared with KK cows (65.5 vs. 56.7 breaths/min). Milk yield ( $=$ 79) did not differ between ADS and KK treatments (36.2 vs. $36.7 \mathrm{~kg} / \mathrm{d}$ ). The use of KK improved cow comfort over $\mathrm{ADS}$, but this did not result in a milk yield difference because in both treatments, the skin temperature was maintained below $35^{\circ} \mathrm{C}$, avoiding milk yield reductions.

Modified tunnel ventilation using evaporative cooling, fans with injection of high pressure mist, and combinations of cooling over feed bunks and free stalls have recently been investigated. In that study, both modified systems used roof-peak ventilation fans. Air was drawn through the sidewall with either cellulose evaporation pads or a narrow slit equipped with a high-pressure mist system. Average day temperature was less than $1.1^{\circ} \mathrm{C}$ different from ambient conditions, and average THI were higher than ambient conditions. The system designs did not effectively alter the environmental conditions enough to reduce heat stress. The effects of barn and system design are important factors in determining the efficiency of evaporative cooling on dairy facilities. Factors critical to the correct design of the system include airflow, air turnover, cross-sectional area, and evaporation potential. It is important to recognize that as air temperature is lowered due to water evaporation, the potential to evaporate moisture from the skin of cattle is also reduced. The net effect of evaporative cooling of air must be greater than the loss of cooling from moisture evaporation from the skin of cattle, or cattle stress will increase rather than decrease under heat stress conditions. An evaluation of 6 tunnel-ventilated tie-stall barns in northeastern Missouri and southeastern Iowa indicated that cattle housed in tie-stall barns equipped with evaporative cooling had lower average respiration rates than those housed in barns without evaporative cooling, (65.7 vs. $70.3 \mathrm{breaths} / \mathrm{min}$ ). Average rectal temperatures were also lower for the cows housed in evaporative-cooled barns. Similar to RR, the greatest differences in rectal temperatures existed during the afternoon. Skin temperatures followed RR and rectal temperatures and were significantly lower for the cattle housed in the barns equipped with evaporative cooling with the greatest differences observed during the afternoon. This study showed significant advantages for the evaporative-cooled and tunnel-ventilated barns in terms of RR, rectal temperatures, and barn environment.

\section{OTHER COOLING SYSTEMS}

Various cooling systems have been evaluated, and air conditioning dairy cows for $24 \mathrm{~h} / \mathrm{d}$ improved $4 \%$ FCM 
yield by $9.6 \%$ in a subtropical environment. However, work in a temperate climate showed that air conditioning was not economical. Zone-cooled cows (cooled air blown over the head and neck) averaged 19\% greater milk yield than controls, although other scientists concluded that a well-designed shade structure provided greater economic returns than additional benefits derived from zone cooling. The costs associated with air conditioning, and facilities necessary to provide an enclosed environment, or ducting for zone cooling have proven cost-prohibitive, and these types of systems are rare today.

\section{EXTENDED LIGHT}

Photoperiod, or the recurring cycle of light and darkness within a 24 -h period, is the most consistent environmental cue across time under natural conditions. It is not surprising then that most terrestrial species have adopted this cue to temporally program long-term physiological processes, especially reproduction. Work over the past $25 \mathrm{yr}$, however, suggests that photoperiod also affects growth, lactation, and immune function in cattle, and photoperiod manipulation is a consideration for dairy animals across the life cycle, even under the intensive management conditions used in the industry today.

Because dairy cattle are not seasonal breeders, the influence of photoperiod was largely ignored relative to other domestic species, where investigation centered on manipulation of the breeding season. The most substantive effect on reproduction in cattle is the acceleration of attainment of puberty under long vs. short days. Studies completed at the University of Wisconsin supported the concept that shifts in photoperiod, rather than ambient temperature fluctuations, drive the physiological processes that underlie early puberty. Relative to cattle on short days, exposure to long days increases the luteinizing hormone response to estradiol. Early puberty may then occur as the restraint of low circulating concentrations of estradiol characteristic of the prepubertal period is overcome at an earlier age in cattle exposed to long days.

Earlier puberty in calves on long days is often associated with more rapid growth and lean tissue accretion relative to calves on short days. Heifers housed under long-day photoperiod experience greater mammary parenchymal growth and reduced mammary fat content relative to those on short days. The response appears to be independent of gonadal steroid changes associated with puberty as both pre- and postpubertal heifers respond to long days. Endocrine changes associated with long-day photoperiod include increases in PRL and insulin-like growth factor-I (IGF-I), although the latter is independent of changes in growth hormone. Photoperiod manipulation in cattle has no effect on spontaneous circulating concentration of ST, ST clearance, or the response to thyrotropin-releasing hormone, although transient responses to growth hormone-releasing hormone have been noted. It appears that lean mass accretion and mammary growth effects of long days are likely due to shifts in circulating PRL and IGF-I rather than changes in ST secretion.

The observation that light manipulation altered secretion of PRL in bull calves led to studies to examine the effect of photoperiod on milk production. A pivotal study from Michigan State University in 1978 revealed that extending the duration of light exposure (i.e., long days) relative to natural day length during the fall and winter caused greater milk yield without affecting composition. Despite later evidence that exogenous PRL did not alter milk yield in cattle during an established lactation, numerous studies have confirmed that initial observation of a galactopoietic effect of long-day photoperiod, and collectively suggest that long days enhance milk yield relative to shorter-day natural photoperiods across production levels and at any stage of lactation. A response of 2 to $2.5 \mathrm{~kg}$ of milk/d is typically observed, and the milk yield effect is followed by an increment in DMI of 1 to $1.5 \mathrm{~kg} / \mathrm{d}$.

A number of mechanisms to explain the stimulatory action of long days during lactation have been proposed, from feeding behavior to endocrine responses. However, feeding behavior is not substantially affected by shifts in the light cycle. Indeed, the increase in DMI of cows on long days occurs after milk yield increases, which supports the concept that milk production pulls DMI rather than greater DMI pushing milk yield. Of the hormonal changes associated with shifts in light, only the long-day increase in IGF-I appears to be consistent with galactopoietic responses. Increases in IGF-I are observed with bST and there is some evidence that local infusion of IGF-I increases milk synthesis rates in goats. Lactating cows (Figure 4), heifers, and steers show increases in IGF-I on long days, although dry cows do not; it is possible that circulating IGF-I in dry cows is masked by the dramatic fluctuations in DMI during that phase of the lactation cycle.

A lack of IGF-I response, however, does not mean that photoperiod manipulation does not affect dry cows. Exposure to short days during the dry period significantly increases milk yield in the subsequent lactation compared with long-day treatment of dry cows (Figure $5)$. The response is present at the onset of lactation and persists for up to $40 \mathrm{wk}$. There is no substantial effect on milk composition or on DMI following parturition, although short days during the dry period improve DMI relative to long days. Indeed, greater intake during late 


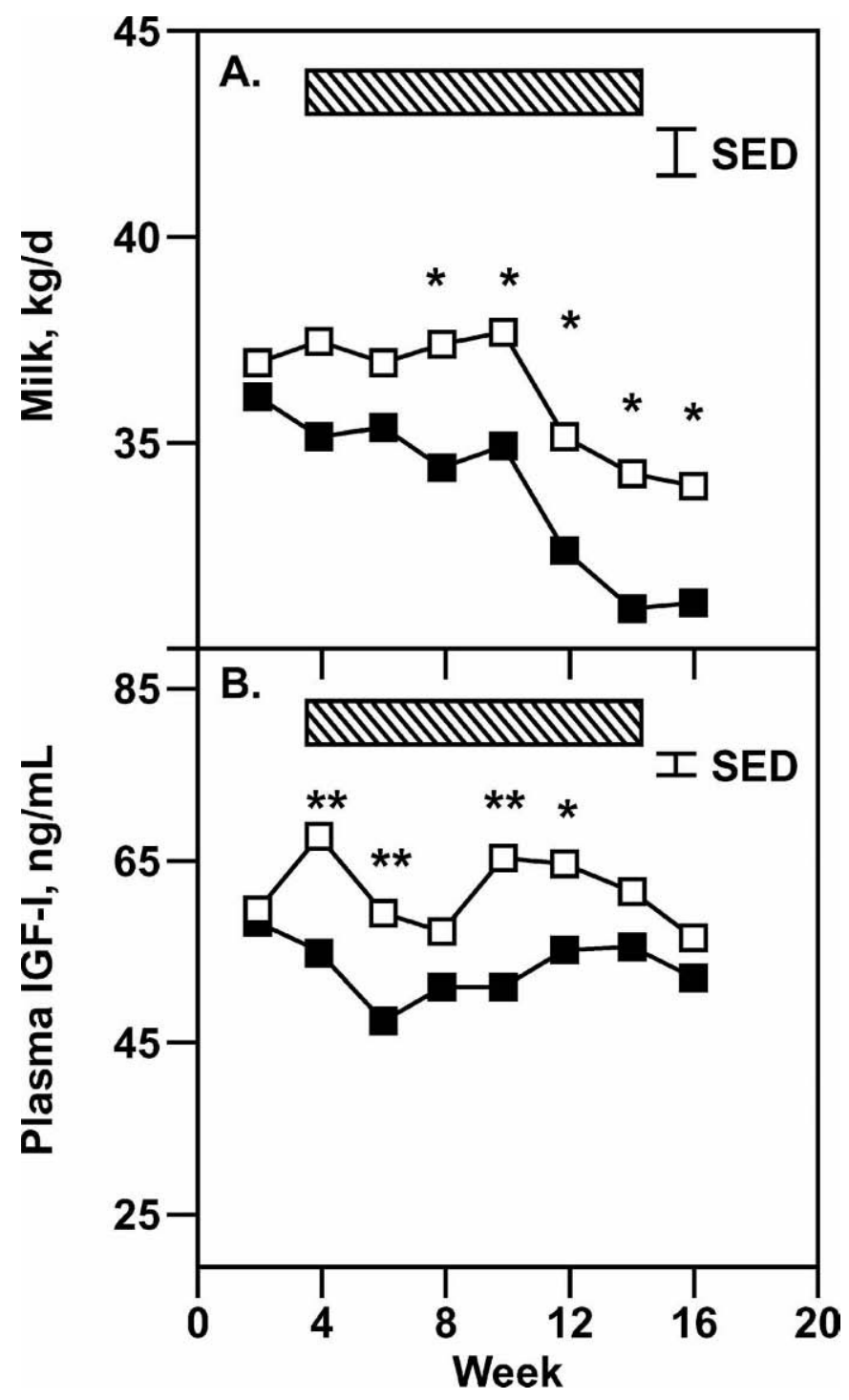

Figure 4. Group means for milk yield and circulating insulin-like growth factor-1 (IGF-I) of cows exposed to long (18 h; $\square$ ) or natural winter $(<13 \mathrm{~h} ; \mathbf{0})$ daily photoperiods. The hatched bars indicate the treatment period, and asterisks indicate differences between groups $(* P<0.05, * * P<0.02)$. Standard error of the difference for comparison between groups is indicated by the vertical bar. A) Each symbol represents the mean yield of cows $(n=20$, long; $n=19$, natural) within that group for the 14-d period. B) Each symbol represents the mean IGF-I of cows $(n=20$, long; $n=19$, natural) within that group for a single blood sample collected on the final day of each 14-d period. Adapted from Dahl et al. (1997).

gestation may account for some of the response PP, but shifts in mammary cell commitment during the transition are also likely to contribute to the response of milk yield. One potential mechanism to explain greater mammary epithelial cell commitment is a relative increase in sensitivity to PRL, the hormone that drives cellular differentiation during the transition into lactation (Figure 6).

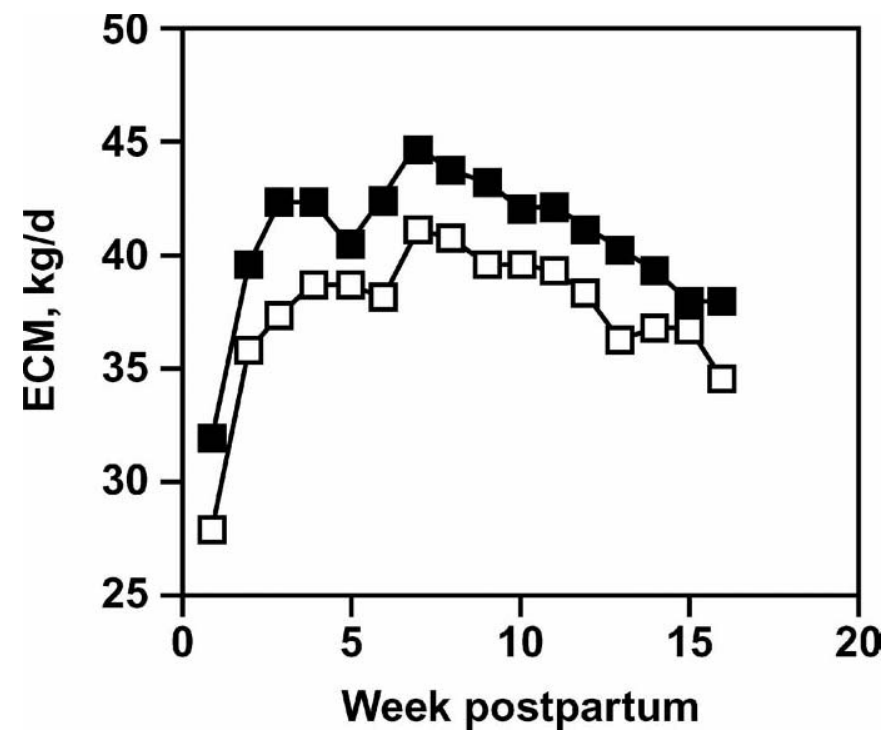

Figure 5. Group means for energy-corrected milk yield (ECM) during the subsequent lactation of cows exposed to long-day $(\square, \mathrm{n}=$ 18) or short-day photoperiod $(\square ; n=16)$ during the dry period $(\sim 60$ d). At calving, all cows returned to natural photoperiodic conditions (January to June in Maryland). Each symbol represents the mean yield of the cows in that group for that week of lactation, through the first $16 \mathrm{wk}$ of lactation. Yields were different between groups ( $P$ $<0.07)$. Adapted from Miller et al. (2000).

As discussed previously, PRL increases under long days relative to short-day exposure. But in addition to circulating hormone concentrations, endocrine responses are also dependent on signal transduction via specific receptors and thus, sensitivity to PRL is a function of PRL-receptor (PRL-R) expression in tissues of interest. Recent evidence suggests that PRL and PRL$R$ expression are inversely related in bovine hepatic, mammary, and immune tissues; therefore, short days are characterized by reduced circulating PRL but greater PRL-R expression compared with long days. Extending this concept back to the responses observed in dry cows housed under short days, those animals would have greater sensitivity to PRL released during the periparturient surge at calving, and one potential outcome would be more extensive mammary epithelial cellular differentiation and commitment to milk component production for that lactation. Such a model is consistent with the observation that the response is present at parturition and extends into lactation even after the stimulus has been removed.

Evidence linking PRL physiology to altered immune function and the observation of seasonal differences in infectious disease incidence has led to the concept that photoperiod could affect immune function through a PRL-dependent mechanism. Testing of this hypothesis revealed that PRL sensitivity was directly proportional 


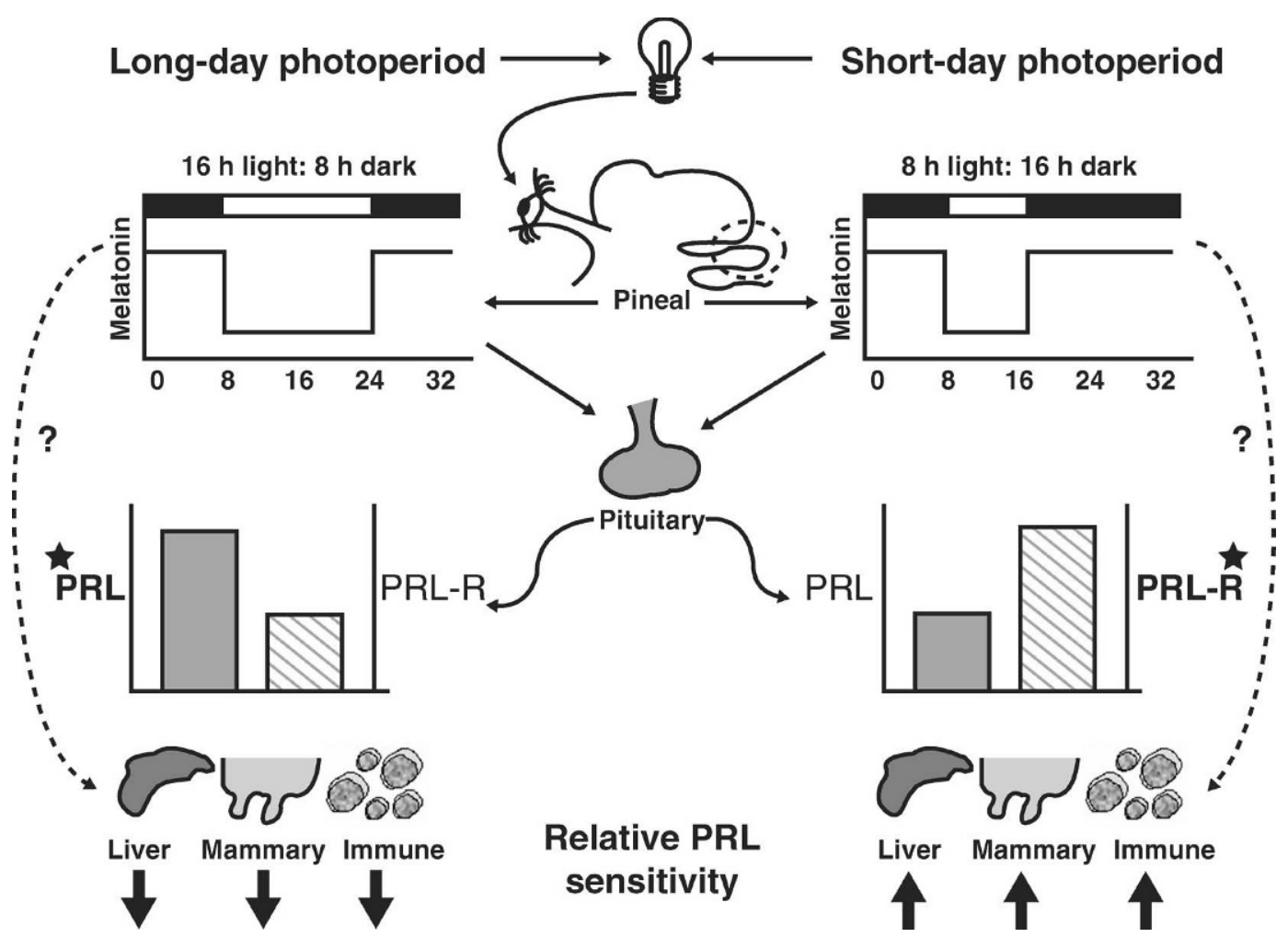

Figure 6. Proposed model of how photoperiod affects changes in bovine physiology via prolactin (PRL) sensitivity. Shifts in the light:dark cycle perceived by photoreceptors in the eye result in changes in the pattern of melatonin secretion from the pineal gland. The pattern of melatonin secretion influences the release of PRL from the anterior pituitary. Long-day photoperiod increases circulating PRL concentration, while decreasing PRL-receptor (PRL-R) mRNA expression in bovine tissues (specifically liver, mammary, and immune). Short-day photoperiod decreases PRL concentrations in circulation while increasing expression of PRL-R mRNA in those same tissues. Therefore, the relative sensitivity to PRL is greater for animals treated with short-day photoperiod relative to long-day photoperiod treated animals (stars indicate relative emphasis under each photoperiod). In addition, it is uncertain whether melatonin has a direct effect on physiological changes observed with photoperiod management. Adapted from Dahl et al. (2004).

to in vitro and in vivo indices of immune function. That is, greater PRL-R expression under short-day exposure was associated with increased lymphocyte proliferation, neutrophil chemotaxis, and a reduction in somatic cell count during the dry period compared with longday exposure. Further confirmation of a PRL-mediated response is based on the observation that exposure to long days combined with bromocriptine treatment to decrease circulating PRL elicited responses similar to those of cows on short days. Also, when tested under in vitro conditions, lymphocytes harvested from cows under short days were significantly more responsive to PRL than those from cows on long days, providing more support for the concept that photoperiodic manipulation of immune function is mediated by changes in PRL sensitivity.

\section{CONCLUSIONS}

Major advances in environmental management of dairy cattle include improved housing and cooling sys- tems, improved ration formulation based on altered requirements during thermal stress, improved reproductive performance using timed insemination approaches to avoid estrus detection, and use of altered photoperiod to maximize lactation performance. Determination that adaptation of animals to thermal stress is a homeorhetic process under endocrine control opens new opportunities to use of endocrine regulation as means of improving thermal tolerance. Substantial efforts are underway to identify specific genes associated with tolerance and sensitivity to thermal stress. Additional work is needed to reduce energy costs of housing and cooling animals during thermal stress. Continued research evaluating methods to improve reproductive performance and nutritional status of thermally stress animals is warranted.

\section{REFERENCES}

Armstrong, D. V. 1994. Heat stress interaction with shade and cooling. J. Dairy Sci. 77:2044-2050. 
Armstrong, D. V., P. E. Hillman, M. J. Meyer, J. F. Smith, and S. R. Stokes. 1999. Heat stress management in freestall barns in the western US. Proceedings of the Western Dairy Management Conference, Las Vegas, NV.

Auchtung, T. L., and G. E. Dahl. 2004. Prolactin mediates photoperiodic immune enhancement: Effects of administration of exogenous prolactin on circulating concentrations, receptor expression, and immune function in steers. Biol. Reprod. 71.

Auchtung, T. L., P. E. Kendall, J. Salak-Johnson, T. B. McFadden, and G. E. Dahl. 2003. Photoperiod and bromocriptine treatment effects on expression of prolactin receptor mRNA in bovine liver, mammary gland and peripheral blood lymphocytes. J. Endocrinol. 179:347-356.

Bray, D. R., R. A. Bucklin, R. Montoya, and R. Gresig. 1994. Cooling methods for dairy housing in the southeastern United States. Trans. ASAE, paper no. 94-4501. ASAE, St. Joseph, MI.

Brouk, M. J., J. F. Smith, and J. P. Harner, III. 2001. Efficiency of modified evaporative cooling in Midwest dairy freestall barns. Pages 412-418 in Livestock and Environment VI: Proc. 6th Int. Symp., Louisville, KY. ASAE, St. Joseph, MI.

Bucklin, R. A., R. W. Bottcher, G. L. Van Wicklen, and M. Czarick. 1993. Reflective roof coatings for heat stress relief in livestock and poultry housing. Appl. Eng. Agric. 9:123-129.

Canton, G. H., D. E. Buffington, and R. J. Collier. 1982. Inspired-air cooling for dairy cows. Trans. ASAE 25:730-734.

Collier, R. J., D. K. Beede, W. W. Thatcher, L. A. Israel, and C. J. Wilcox. 1982a. Influences of environment and its modification on dairy animal health and production. J. Dairy Sci. 65:2213-2227.

Collier, R. J., S. G. Doelger, H. H. Head, W. W. Thatcher, and C. J. Wilcox. 1982b. Effects of heat stress during pregnancy on maternal hormone concentrations, calf birth weight and postpartum milk yield of Holstein cows. J. Anim. Sci. 54:309-319.

Dahl, G. E., T. L. Auchtung, and E. D. Reid. 2004 Manipulating milk production in early lactation through photoperiod changes and milking frequency. Pages 675-685 in The Veterinary Clinics of North America: Managing the Transition Cow to Optimize Health and Productivity. N. Cook and K. Nordlund, ed. Elsevier, Philadelphia, PA

Dahl, G. E., T. H. Elsasser, A. V. Capuco, R. A. Erdman, and R. R. Peters. 1997. Effects of long daily photoperiod on milk yield and circulating insulin-like growth factor-1 (IGF-1). J. Dairy Sci. 80:2784-2789.

Dahl, G. E., and D. Petitclerc. 2003. Management of photoperiod in the dairy herd for improved production and health. J. Anim. Sci. 81(Suppl. 3):11-17.

Guzeloglu, A., J. D. Ambrose, T. Kassa, T. Diaz, M. J. Thatcher, and W. W. Thatcher. 2001. Long term follicular dynamics and biochemical characteristics of dominant follicles in dairy cows subjected to acute heat stress. Anim. Reprod. Sci. 66:15-34.

Hansen, P. J. 1985. Seasonal modulation of puberty and the postpartum anestrus in cattle. Livest. Prod. Sci. 12:309-327.

Hansen, P. J., and C. F. Arechiga. 1999. Strategies for managing reproduction in the heat-stressed dairy cow. J. Anim. Sci. 77(Suppl. 2):36-50

Hansen, P. J. 2004. Physiological and cellular adaptations of zebu cattle to thermal stress. Anim. Reprod. Sci. 82-83:349-360.

Her, E., D. Wolfenson, I. Flamembaum, Y. Folman, M. Kaim, and A. Berman. 1988. Thermal, productive, and reproductive responses of high yielding cows exposed to short-term cooling in summer. J. Dairy Sci. 71:1085-1092.

Igono, M. O., H. D. Johnson, B. J. Steevens, G. F. Krause, and M. D. Shanklin. 1987. Physiological, productive, and economic bene- fits of shade, spray, and fan system versus shade for Holstein cows during summer heat. J. Dairy Sci. 70:1069-1079.

Igono, M. O., B. J. Steevens, M. D. Shanklin, and H. D. Johnson. 1985. Spray cooling effects on milk production, milk and rectal temperatures of cows during a moderate temperature summer season. J. Dairy Sci. 68:979-985.

Means, S. L., R. A. Bucklin, R. A. Nordstedt, D. K. Beede, D. R. Bray, C. J. Wilcox, and W. K. Sanchez. 1992. Water application rates for a sprinkler and fan dairy cooling system in hot, humid climates. Appl. Eng. Agric. 8:375-379.

Miller, A. R. E., L. W. Douglass, R. A. Erdman, and G. E. Dahl. 2000. Effects of photoperiodic manipulation during the dry period of dairy cows. J. Dairy Sci. 83:962-967.

Olson, T. A., C. Lucena, C. C. Chase, Jr., and A. C. Hammond. 2003. Evidence of a major gene influencing hair length and heat tolerance in Bos taurus cattle. J. Anim. Sci. 81:80-90.

Peters, R. R., L. T. Chapin, K. B. Leining, and H. A. Tucker. 1978. Supplemental lighting stimulates growth and lactation in cattle. Science 199:911-912.

Petitclerc, D., R. D. Kineman, S. A. Zinn, and H. A. Tucker. 1985 Mammary growth response of Holstein heifers to photoperiod. J. Dairy Sci. 68:86-90.

Ravagnolo, O., and I. Misztal. 2002. Studies on genetics of heat tolerance in dairy cattle with reduced weather information or cluster analysis. J. Dairy Sci. 85:1586-1589.

Roth, Z., A. Arav, A. Bor, Y. Zeron, R. Braw-Tal, and D. Wolfenson. 2001. Improvement of quality of oocytes collected in the autumn by enhanced removal of impaired follicles from previously heatstressed cows. Reproduction 122:737-744.

Rutledge, J. J. 2001. Use of embryo transfer and IVF to bypass effects of heat stress. Theriogenology 55:105-111.

Ryan, D. P., M. P. Boland, E. Kopel, D. Armstrong, L. Munyakazi, R. A. Godke, and R. H. Ingraham. 1992. Evaluating two different evaporative cooling management systems for dairy cows in a hot, dry climate. J. Dairy Sci. 75:1052-1059.

Smith, J. F., J. P Harner III, and M. J. Brouk. 2001. Keeping cows cool, where do I start? Kansas State University, Manhattan.

St-Pierre, N., B. Cobanov, and G. Schnitkey 2003. Economic losses from heat stress by U.S. livestock industries. J. Dairy Sci. 86(E. Suppl.):E52-E77.

Strickland, J. T., R. A. Bucklin, R. A. Nordstedt, D. K. Beede, and D. R. Bray. 1989. Sprinkler and fan cooling systems for dairy cows in hot, humid climates. Appl. Eng. Agric. 5:231-236.

Takamitsu, A., S. Takahashi, M. Kurihara, and S. Kume. 1987. Effect of an evaporative cooling procedure on the physiological responses of lactating dairy cows in a hot, humid climate. Jpn. J. Zootechnol. Sci. 58:790-796.

Taylor, S. E., D. E. Buffington, R. J. Collier, and M. A. DeLorenzo. 1986. Evaporative cooling for dairy cows in Florida. ASAE paper no. 86-4022. ASAE, St. Joseph, MI.

Thatcher, W. W. 1974. Effects of season, climate, and temperature on reproduction and lactation. J. Dairy Sci. 57:360-368.

Turner, L. W. 1998. Fan and high-pressure mist (fog) systems performance for cooling lactating dairy cows. Pages 201-208 in Proc. 4th Int. Dairy Housing Conf., St. Joseph, MI. ASAE, St. Joseph, MI.

West, J. W. 1999. Nutritional strategies for managing the heatstressed dairy cow. J. Anim. Sci. 77(Suppl. 2):21-35.

West, J. W. 2003. Effects of heat-stress on production in dairy cattle. J. Dairy Sci. 86:2131-2144.

Wiersma, F., and D. V. Armstrong. 1983. Cooling dairy cattle in the holding pen. ASAE paper no. 83-4507. ASAE, St. Joseph, MI. 